number of periods - no attempt had been made to make the table complete-it would not be difficult to find a period near any specified period, especially if one were allowed to consider multiples and submultiples. He then discussed the two chief meteorological cycles, the Brückner cycle and the sunspot cycle. The hundred-year record of London rainfall has been analysed for a 35-year period, and a curve added to a diagram of monthly totals to show on the same scale the contribution of the cycle to the total rainfall. The amplitude of the cycle is absolutely insignificant in comparison with the monthly variations. Dr. Simpson admitted that there is an appreciable correlation between sunspots and meteorological factors, but as sunspots have no true periodicity they cannot introduce a periodic term into meteorological phenomena.

Turning to Sir William Beveridge's results Dr. Simpson regretted that he had not seen Sir William's recent paper in the Journal of the Statistical Society but only his papers in the Economic Journal, because the periods on which Sir William appears now to rely are different. He was prepared to admit that Sir William Beveridge had discovered certain periodicities in his curve of prices of wheat which were many times greater than one would expect by chance, but he strongly contested that these were meteorological periodicities. Sir William Beveridge laid great stress on a periodicity discovered by Capt. Brunt in Greenwich temperature, 5.I years, which coincided with one of his cycles, but it was pointed out that Capt. Brunt discovered 9 cycles, four of which had greater and four smaller amplitudes than this particular cycle. Also Capt. Brunt's cycle of 5.I years reduced the standard deviation of mean monthly temperatures at Greenwich only from 2.80 to $2 \cdot 77$, an insignificant change.

Dr. Simpson also criticised Sir William Beveridge's synthetic curve and asked why that curve should be compared with rainfall. There appeared to him no more reason why it should apply to rainfall than to any other meteorological or economic or even biological factor which might conceivably affect a harvest. In conclusion, admitting all that Sir William claimed to have done, he did not think that a prediction which gave a correlation coefficient with actuality of only $0.3^{8}$ had any practical value. When Sir William had increased his correlation coefficient to about 0.83 he would be a valuable forecaster, but not until then.

Mr. Udny Yule said that the comments of Dr. Simpson seemed to him unfair. It must certainly be recognised that mere inspection of data was wholly inadequate and might lead to unfounded ideas as to the existence of periodicities, but this criticism had no bearing on work carried out by the periodogram method. He felt a good deal more doubt than some previous speakers on the question whether crop cycles were or were not a vital factor in the general economic cycle, which required far more study. From the statistical side the most important work now to be done is the determination of the crop cycles in areas other than Western Europe, e.g. South America and India: in so far as crop cycles are an important factor in the economic cycle, the resultant in any one country must be a complex effect dependent on the sources of its raw materials. On the side of economic theory it seemed to him there is also work to be done. The treatment of economics is in general static. The economist is too apt to tell us that " in the long run " a pendulum will hang vertically, whereas the whole interest of the pendulum is that it swings, and the problem is why it swings and how it swings. The treatment of economics should be dynamic. The question might be asked, for example, whether there is not an equation relating production not merely to price but to price and its time differentials, an equation which might (or in given circumstances might not) have a periodic solution.

Prof. H. H. Turner considered that we should be grateful to Sir William Beveridge, first, for producing a long series of annual values, going back much further than our longest rainfall record; secondly, for having himself analysed them completely by the periodogram method, so that others can profit by his analysis; and thirdly, for two considerable successes in the outcome. One of these is remarkable. He had succeeded in forecasting the weather in some sort-a rare, if not unique, achievement up to the present. The other success consisted in isolating several periods which must be further investigated. The periodogram gives us only the beginning, not the end of an investigation. Having obtained, for example, the definite suggestion of a I5-day period we must then see how it behaves throughout the series; the maximum phase seems to oscillate in this case. Such oscillations frequently occur in manifestations of periodicity which may itself be quite regular; thus, the rotation of the earth is quite regular, but one of its manifestations is sunrise, which swings to and fro. Sir William Beveridge had given us a good start, which it is to be hoped will be followed up.

\title{
Geology of the North Sea Basin.
}

T. HE long-standing custom of devoting at least part of a session of the Geological Section of the British Association to matters pertaining to the geology of the district in which the meeting is being held, was extended this year to the consideration of the wider question of the geological history of the North Sea basin, the discussion on this subject being the first of a series held in different sections on various aspects of the North Sea.

The discussion was opened by Prof. P. F. Kendall, president of the section, and was continued by Mr. J. O. Borley, of the Fisheries Research Laboratory, Lowestoft, who described the nature and distribution of the deposits now being laid down. Mr. Thomas Sheppard dealt with the geology of the Hull district, and $\mathrm{Mr}$. C. Thompson contributed an interesting paper on the present rate of erosion of the coast of Holderness.

The main tectonic lines of the British Isles and of the neighbouring area, the North Sea, were produced prior to the formation of the Permian rocks, the three main axes of folding being the Caledonian (N.E. and S.W.), the Pennine (N. and S.), and the Armorican (W. and E. approximately). Later movements, for the most part along these old lines, were responsible for the changes in the distribution of land and water which have taken place.

The region now occupied by the North Sea appears to have been an area of depression since a very remote period. Thus it is found that movements which took place during late Carboniferous times and during the period, unrepresented by any deposits in Europe, that elapsed before the deposition of the Permian rocks, caused the coal measures to dip into the basin in Holland and Belgium, in Northumberland and Durham, and probably also in Lincolnshire, to reemerge at Ibbenbüren. 
The sinking of the basin thus formed appears to have continued intermittently in Permian, Jurassic, and Cretaceous times, the Permian and Jurassic deposits in the Durham-Yorkshire area being thicker than in almost any other part of Britain, and the Lower Cretaceous beds (the Speeton clay), being of a deep water type, contrasting strongly with the shallow water and estuarine deposits of that age to be found in parts of Britain more remote from the basin. The chalk also reaches its maximum British development on the East Coast.

After the formation of the chalk, the area was uplifted and much denudation took place prior to the deposition of the Woolwich and Reading beds and London Clay, which marks the commencement of a further downward movement. These Lower Tertiary beds still occupy the London and Hampshire basins and extend below the southern part of the North Sea. Prior to the great denudation which followed the uplift in Miocene and early Pliocene times, they doubtless occupied a much wider areathe then basin of the North Sea with its embayments and estuaries.

Then followed intermittent movements of the Armorican folds in the south of England, Northern France and Belgium extending into Pliocene (Diestian) times.

From this time onwards it is possible to trace the southern and western shores of the North Sea with some degree of accuracy. In Diestian times, Harmer suggests that the coast-line ran from the neighbourhood of Dover across the straits into Belgium, the shore deposits being represented by the Lenham beds and the Diestian of Belgium. The later Pliocene deposits indicate a gradual retreat of the sea to the northwards, the fossils of the Red Crag and Norwich Crag showing a gradual increase in the number of living as compared with extinct species as they are traced from Essex to the Wash.

At the close of Pliocene time much of the southern portion of the North Sea Basin must have been lowlying land, and across this meandered the great rivers of Northern Europe. The estuary of the Rhine, according to Harmer, crossed Norfolk; and in it were laid down the Chillesford beds.

To the north of the Humber the coast-line of this period has been traced by a line of buried cliff with accompanying beach deposits running from Hessle on the Humber, inland to the west of Beverley, and emerging on the line of the existing coast at Sewerby, between Bridlington and Flamborough Head. The plain of marine denudation in front of this old coastline has been charted and contoured by means of information obtained from numerous borings which have been put down in search of water in the Plain of Holderness.

The next phase was a retreat of the sea and the formation of sand dunes along the foot of the cliff. The geological date is indicated by the occurrence of Elephas antiquus, Rhinoceros leptorhinus, and hippopotamus in the deposits, a fauna which accompanies implements of Chellean type in the south of England.
Throughout Pliocene times, a gradual refrigeration of the climate was in progress, as is shown by the molluscan fossils and also by the land flora, where remains of this have been preserved; and the next episode was the formation of a great ice-sheet having its radiant point in the neighbourhood of the Gulf of Bothnia. This appears to have displaced the waters of the North Sea at least as far south as the coast of Essex. Retreats and readvances took place, but the final retreat of the ice can be traced with great detail and precision by the drainage phenomena developed along its margin up to its last contact with British shores on the Ord of Caithness.

Oscillations of level accompanied the retreat of the ice and raised beaches were left, but on the completion of the withdrawal the land stood about 80 feet higher than at present. The southern part of the North Sea became a marshy plain, peat bogs covered much of its surface and forests clothed its margins, while great rivers such as the Rhine, Thames, and Weser meandered through it.

A depression to the present level then ensued and the great shallow bay of the North Sea south of the Dogger Bank was formed. The sea ran up the estuaries, and thus the Humber itself and its tributary the Hull came into being.

The work now being carried out by the officers of the Fisheries Board is throwing much light on the distribution of the various grades of material accumulating on the floor of the North Sea at the present time. Both the mineralogical character and the size of grain of the material are being investigated, though, of course, the latter is of more importance from the immediate point of view of fisheries, since it controls to a large extent the distribution of life.

By means of experiments with floats the direction of the main surface currents has been determined, and the maps exhibited by Mr. Borley showed that the floor deposits were spread out under the influence of the same movements. Several different types of material exist on the coast, but in each the grading of the deposits, coarse to fine, is in the general direction of the currents already determined by other means.

Along a great part of the east coast of Britain the North Sea is at present eroding the cliffs at a fairly rapid rate, and this has been measured by Mr. Thompson in the case of the coast of Holderness, which consists of glacial deposits. His method was to take the six-inch Ordnance Survey map published in 1852 and to measure thereon the lengths of all easily identifiable lines running at right angles to the coast, and then to measure up the remains of these lines on the ground. In this manner it was possible to draw the coast-line as it is to-day on the map of 1852 and thus to indicate the strip of land lost to the sea in the last seventy years. This strip varies considerably in width in different parts of the coast, there being a few points at which erosion is practically nil while at others it has caused serious loss.

\section{New Japanese Botanical Serials.}

DURING the last few decades the universities and colleges of Japan have produced a large number of scientific investigators, many of whom have continued postgraduate training for several years in Europe or America. The result is that in Eastern Asia a large number of well-equipped scientific investigators are now actively prosecuting research and there is a danger that, working in a field still far distant as regards practicable modes of communication, their work may not be sufficiently known in Europe, with corresponding loss of efficiency to the workers in both continents. Japanese scientific leaders are evidently alive to the danger, and the reopening of extensive scientific contact following the gradual cessation of war conditions has been followed by the organisation and issue of a number 